\title{
El arbitrio de la hierba "provechosa" del Paraguay de 1637. Experiencia y práctica en la construcción de saberes locales de Indias a través del Atlántico
}

Fernando Bouza*

Resumen: La propuesta de establecer una imposición nueva sobre el consumo de hierba mate paraguaya en 1637 permite analizar los mecanismos por los que el gobierno hispano de Indias tomaba algunas de sus decisiones a mediados del siglo XVII a partir de la construcción de un saber local basado en un conocimiento práctico y experimentado. La búsqueda de personas que pudiesen testimoniar dicho conocimiento se convertía en una exigencia en unos momentos en los que los criollos americanos pretendían ingresar por derecho propio en el Consejo de Indias. Al mismo tiempo, se ofrecen noticias hasta ahora inéditas sobre la producción, la distribución y el consumo de hierba mate desde Paraguay, Río de la Plata y Perú hasta alcanzar incluso el lejano mercado de la corte de los Austrias hispanos.

Palabras clave: Saberes locales. Saberes prácticos. Gobierno de Indias. Paraguay. Yerba mate (Ilex Paraguaiensis).

El padre Antonio Ruiz de Montoya viajó en 1637 a la corte de Madrid como procurador de la Compañía de Jesús en Paraguay

\footnotetext{
* Professor Doutor Catedratico em História Moderna da Universidad Complutense de Madrid. E-mail: ortegal@ghis.ucm.es
}

Anos 90, Porto Alegre, v. 24, n. 45, p. 73-100, jul. 2017 
y regresó a las Indias en 1643 habiendo desarrollado importantes labores de mediación en Madrid, ante los órganos de despacho y gobierno de la Monarquía y ante el propio rey Felipe IV ${ }^{1}$ (ROUILLON ARRÓSPIDE, 1997; AGUILAR, 2002; FEITLER, 2007). En el marco de esta imponente actividad desarrollada en la corte también hubo, por supuesto, un capítulo tipográfico (PALOMO, 2016).

Además de dar a la imprenta varios memoriales sobre los "agravios" paulistas ${ }^{2}$ (FEITLER, 2007) y su resonante Conquista espiritual hecha por los religiosos de la Compañia de Jesús en las provincias del Paraguay, Paraná, Uruguay y Tape $e^{3}$, Ruiz de Montoya publicó cuatro obras sobre la lengua guaraní (NEUMANN, 2015), cuyos manuscritos había traído consigo a Europa desde América, pues las aprobaciones eclesiástica y de su orden están fechadas en Buenos Aires en 1637. Se trataba, obviamente, del Tesoro ${ }^{4}$, el Catecismo ${ }^{5}$ y el doble Arte y bocabulario de la lengua guarami $i^{6}$ para los que el jesuita había obtenido privilegio real único por un período de diez años (Madrid, 25 de marzo de 1639).

Aunque puestos al amparo del mismo privilegio, los cuatro títulos salieron de dos oficinas tipográficas distintas, formando tres volúmenes con sus propios pies de imprenta. Pese a ello, aparecieron con idénticas aprobaciones del Provincial de la Compañía y del Vicariato en Buenos Aires (4 de octubre de 1637), así como con la licencia del vicariato madrileño (14 de febrero de 1639) y con la aprobación a propuesta del Consejo de Castilla que Lourenço de Mendonça, Prelado de Río de Janeiro, firmó en Madrid a 7 de marzo de $1639^{7}$. En el fondo, el único de los paratextos tipográficos que varía de obra en obra son las fes de erratas. Al corresponder a textos distintos, tenían obviamente que ser diferentes, como también habían variado los fallos de los oficiales de imprenta que se enfrentaron al reto tipográfico de componer un texto verdaderamente singular (POLLACK, 2014).

En la Vida prodigiosa de Jarque, la biografía clásica de Ruiz de Montoya, se evocan las dificultades que entrañó la impresión, "por ser lengua peregrina, y necesarios nueuos caracteres, anotaciones y puntos para esprimir las pronunciaciones diuersas que unas mismas letras tienen de la Española, y Latina". Mientras duró el período de estampación, el propio jesuita limeño asistió a los impresores, 
quienes "se hallauan confusos; y todo lo auía de allanar el Autor, con su trauajo y paciencia".

Aunque en la corte de los Austrias no existía ni siquiera un pálido reflejo de un establecimiento como la tipografía políglota dependiente de Propaganda Fide en Roma (PIZZORUSSO, 2004), se logró superar el reto de la estampación fundiéndose caracteres especiales de imprenta atribuidos a los sonidos de la lengua guaraní. No obstante, quedaba un último obstáculo. ¿Cómo realizar en el Madrid de 1639 la preceptiva revisión de textos impresos en guaraní a la luz de los originales manuscritos que el Consejo de Castilla exigía y que, obviamente, no se podía confiar al autor?

La respuesta es sencilla: quien se ocupó la revisión de los textos para localizar y corregir las erratas que se habían deslizado en ellos no fue otro que Lourenço de Mendonça, obispo electo de Río de Janeiro (RUBERT, 1976; CARDIM, 2008; CURTO, 2010). De esta forma, si la Conquista espiritual de Montoya contiene unas erratas firmadas, como era habitual entonces, por el corrector Licenciado Murcia de la Llana (DÍAZ MORENO, 2009), las de su Tesoro (Madrid, 22 de noviembre de 1639) y las del Arte y bocabulario están firmadas por el Prelado de Río, siendo posible conjeturar que también corrigió el texto del Catecismo, aunque su fe de erratas va sin firmar. En su antes citada aprobación de marzo de 1639, Mendonça proclamaba que "he visto, y leído [...] escrito en la lengua de las dichas Prouincias, en las quales he estado, y por la experiencia que tengo dellas, y de sus lenguas, y de otras del Perú", pero, además, "lo conferí todo con otras personas de allá, y con algunos Indios de las dichas Prouincias, y otros de mi Diócesis del Brasil, prácticos y ladinos, assí en nuestra lengua, como en aquella suya" "10.

El Consejo de Castilla tuvo que recurrir a Lourenço de Mendonça para aprobar los libros de Ruiz de Montoya y, asimismo, para corregir sus erratas en el caso de los tratados bilingües. Además de comprobarse una vez más la permeabilidad biográfica de las fronteras entre Brasil y el Río de la Plata circa 1640, el prelado fluminense fue elegido por su experiencia y por el "saber" que se derivaba directamente de ella y de las personas prácticas con las que había podido conferir su contenido. 
Sin duda, la estancia en Madrid de Antonio Ruiz de Montoya marcó de forma sustancial - y jesuítica - la construcción de un saber autorizado (DE CASTELNAU-L'ESTOILE; COPETE; MALDAVSKY; ZUPANOV, 2011) en materias paraguayas (WILDE, 2009) en la corte de la Monarquía de los Austrias hispanos. El calado de la influencia de sus obras se puede testimoniar si, a título de ejemplo, se considera cuáles son los títulos relacionados de forma directa con Paraguay que aparecen en el inventario de la bien surtida biblioteca de Lorenzo Ramírez de Prado. Junto a sendos ejemplares de la Relación de los martirios de noviembre de 1628, cuya impresión promovió Giovanni Battista Ferrufino, y de las Litterae annuae provinciae Paraquariae Societatis Iesu de 1636, figuran hasta cuatro entradas correspondientes a obras de Antonio Ruiz de Montoya, la Conquista, el Tesoro, el Arte y el Catecismo ${ }^{11}$.

La importancia extraordinaria de la estancia en Madrid del procurador de la Compañía de Jesús no debe hacer olvidar que en esa misma década de 1630 otros "andantes en corte" habían venido hasta ella para tratar materias relativas al Paraguay. Uno de ellos fue el agustino fray Gonzalo del Valle que, llegado de Indias, promovió una negociación sobre el estanco de la hierba mate en enero de 1637. Con este motivo, la Monarquía tuvo que dar muestras de qué sabía sobre las provincias del Paraguay y cómo podía aprender más sobre ellas.

Uno de los primeros testimonios de la llegada de la hierba mate a la corte real lo proporciona Antonio de León Pinelo en su justamente célebre Qüestión moral, donde, como es bien sabido, no sólo se ocupa del chocolate y de si éste "quebranta el ayuno eclesiástico"12. En este tratado publicado en 1636, pero concluido tres años antes, el relator del Consejo de Indias pasa revista en este tratado a toda otra serie de productos americanos llegados a Europa (PÉREZ SAMPER, 1996), algunos de los cuales se consumían, e incluso se vendían, en la corte de Madrid. Sus observaciones son muy sugerentes a este último respecto.

Por ejemplo, al señalar que en Nueva España se mezclaba el atole de maíz con chocolate, añade "que ya se usa también en esta Corte por algunos Mexicanos"13. A propósito de la preparación del chuño en Perú, explica que "las Papas [...] son de la misma forma 
que las criadillas de tierra, aunque mayores, más blandas y esponjosas" y que "en esta Corte se venden ya muchas con nombre de raíces", especificando que, mientras "los Indios le mezclan pimiento" a la pasta seca del tubérculo, "los Españoles [le mezclan] azúcar y especias aromáticas"". Por último, también se hace eco de que "se ha estendido por todo el Perú, i a vezes llegado a esta Corte" una hierba que "por antonomasia le ha quedado el nombre de Yerua del Paraguay", la cual se "echa en agua caliente, i en un mate"15.

La veracidad de las afirmaciones de Pinelo puede ser atestiguada de manera fehaciente. En lo que respecta al consumo y venta de chocolate, bastará recordar que, por ejemplo, la Tassa de los precios de 1628 ordenaba que la libra del chocolate novohispano - "de Guajaca"- se vendiese a doce reales y que "lo hecho en Seuilla con materiales de Indias" costase ocho reales ${ }^{16}$. Algo más complicado es testimoniar el consumo cortesano de patatas, papas o raíces, aunque es posible documentar que Inés de Zúñiga, esposa de Olivares, conseguía un pasaporte de aduana en 1633 para "algunas caxas de patata en conserua” que enviaba desde Madrid a su hermano Manuel de Zúñiga, por entonces virrey de Nápoles ${ }^{17}$. Sobre la hierba del Paraguay, debe decirse que, en efecto, se consumía en la corte de los Austrias en la década de 1630 y que, como se ha adelantado, se estaba discutiendo abiertamente sobre ella en enero de 1637.

La discusión sobre el mate respondió a un memorial remitido a Felipe IV por el agustino fray Gonzalo del Valle en el que se proponía el establecimiento de un estanco real que, bien administrado directamente por oficiales de la Corona bien arrendado a uno o más particulares, sacase partido hacendístico a la venta de hierba del Paraguay, cuyo consumo se supone en crecimiento constante y se compara con el del tabaco o el chocolate. Una vez consultado en el seno de una junta particular, en la que entraron Lorenzo Ramírez de Prado, Bartolomé Morquecho y Rodrigo Jurado, el rey ordenó que se avanzase en la realización de este arbitrio en forma de estanco o, según las preferencias de la Junta, como una imposición, recompensándose a su promotor con el cuatro por ciento de la renta que llegase a producir ${ }^{18}$.

El objetivo de este estudio es dar a conocer la documentación generada en torno a lo propuesto por Gonzalo del Valle en 1637. 
En ella, se ofrecen interesantes noticias sobre la producción, el consumo y la distribución indiana de la hierba del Paraguay en la década de 1630 (GARAVAGLIA, 1981, 1983). Pero, además, permite analizar el proceso por el que en la corte madrileña de la década de 1630 se obtenían informaciones consideradas suficientemente autorizadas y fehacientes como para fundamentar la toma de decisiones sobre una materia que, aunque no desconocida para el Consejo, suponía una relativa novedad en los asuntos de su despacho y gobierno.

En el memorial que dio origen a la discusión sobre la hierba de Paraguay de 1637, Gonzalo del Valle se presenta como fraile agustino, natural de Puebla de Don Gonzalo", llegado "desde las Indias donde a assistido de algunos años a esta parte" 20 . Del desarrollo de la negociación, se deduce que había abandonado América sin licencia, ni de los prelados de su orden ni de las autoridades competentes en Indias $^{21}$, sin que sea posible precisar cuándo había llegado a Madrid. No obstante, el fraile asegura que se había embarcado en el mismo navío que el también agustino Fernando de Abreu, quien, según León Pinelo, se hallaba residiendo en la corte desde $1636^{22}$.

Por razones que se ignoran ${ }^{23}$, Gonzalo del Valle encabezó su propuesta diciendo que actuaba en nombre de un hermano suyo llamado Bartolomé Alonso del Valle ${ }^{24}$, ausente entonces de la corte. Pese a ello, en la documentación se le cita a él como promotor y beneficiario del arbitrio. De hecho, fue invitado a hablar ante la Junta para facilitar noticias complementarias a lo expuesto en su memorial, componiendo, además, un segundo escrito con el ánimo de solventar algunas de las dudas abiertas a lo largo de la negociación.

La naturaleza de la hierba del Paraguay sobre la que sugería la creación de un estanco era descrita de la siguiente manera:

"[hay en Mbaracayú] unos árboles que no se hallan en otras partes y son a manera de encinas y no dan más fruto que hojas que son como de naranjo, tan saludables que secándolas i haciéndolas poluos, bebidos en agua más caliente que tiuia preseruan de toda enfermedad contajiosa (como son tabardillos, fiebres y otras), haçen a los hombres robustos para el trabajo, valientes para la guerra, y les dilata la vida".

Anos 90, Porto Alegre, v. 24, n. 45, p. 73-100, jul. 2017 
Aunque la atención del memorial y de los interesados cálculos de fray Gonzalo se centran en Mbaracayú, no obstante conviene resaltar que el agustino indica también que "otros árboles semejantes a los referidos se hallan en la Prouincia del Vruray, y en la del Tapé, que son vecinas a la del Paraguay". Estas provincias "están pobladas de indios sin habitación de españoles", por lo que "los Padres de la Compañía de Jesús tienen repartidas algunas dotrinas, o reducciones (como ellos llaman)". También los jesuitas trajinan con sus hojas "y las sacan a vender fuera a otras Prouincias, aunque - a juicio de Gonzalo del Valle - no son tenidas estas hojas por tan saludables como las primeras ni son tan estimadas, mas con todo esso se gastan, y venden, aunque a menor precio".

En el memorial de 1637 no se califica a la hierba de "santa", como había hecho Antonio Vázquez de Espinosa en el capítulo "De otras prouincias y Naciones, y del Maracayû de donde cogen la yerba Santa que llaman del Paraguay" en 1629 (VÁZQUEZ DE ESPINOSA, 1948, p. 636-637). Sin embargo, por razones obvias, el agustino enfatiza al máximo sus calidades, señalando, en cuanto a su origen, que algunos "afirman por tradición que fue remedio y medicina contra toda enfermedad dada por el Apóstol S. Thomé a sus passados".

La presencia apostólica en Indias se repetía con insistencia en la época (SÁNCHEZ, 1994, p. 216-218). En 1639, por ejemplo, coincidían en darla por segura tanto el agustino Antonio de la Calancha $^{25}$ como Antonio Ruiz de Montoya ${ }^{26}$. Sin embargo, éste último no aceptaba que se relacionase la yerba con santidad alguna, sino que, por el contrario, parecía maldecirla al vincularla estrechamente a los agravios que se hacían a los indígenas ${ }^{27}$. De esta forma, mientras que Gonzalo del Valle, en 1637, dice que ha viajado a Madrid con algunos polvos para hacer el mate - y, además, "dirá de la manera en que se toman" -, Montoya asegura que "nunca la he prouado" 28 , pese a que admite haberse alimentado con "los ordinarios manjares que los Indios comúnmente usan" 29 .

A la hora de encarecer sus muchos beneficios, el agustino señalaba que "comúnmente los españoles llaman a esta ierua la Plouechosa". A su juicio, era éste un producto cuyo consumo estaba creciendo de forma tan acelerada que a la Hacienda regia le convenía 
sacarle el mejor partido posible. Y, esto, tanto a la de Mbaracayú como a la de las reducciones jesuíticas, porque de ella "ai de pressente tanto gasto en el Perú como en la Nueua España del cacao de que se haçe el chocolate".

Como ya se ha señalado, para estudiar la propuesta de la hierba del Paraguay se reunieron en junta Ramírez de Prado, Morquecho y Jurado, tres figuras bien conocidas y vinculadas a Indias y a Hacienda. Teniendo en cuenta que la propuesta pasaba por el establecimiento de un estanco regio sobre un consumo, las cuestiones que esta Junta tenía que dilucidar era quiénes, cuántos y dónde se consumía, pero, además, a qué precios y en qué cantidades, sin olvidar informaciones a propósito de cómo era su comercio y cuáles las rutas de su distribución que iba a estancarse.

A la luz de las noticias que Gonzalo del Valle ofrece en 1637, la hierba constituía "el principal trato de aquella tierra", trasladándose "de ordinario en barcos" por el Paraná hasta Asunción, para alcanzar a Tucumán y a Buenos Aires "de donde se diuierte a otras diferentes Prouincias". Fray Gonzalo no olvida señalar que mientras "los naturales la toman de ordinario casi todo el día, y la tienen por sustento", en cambio "los españoles [la consumen] con más moderaçión, aunque suelen usar della una o dos veçes al día”.

La posibilidad de transformar su comercio en un estanco regio nacía de que están "todos los árboles en tierras Realengas, con que a nadie se hace perjuicio", calculando que "importará [...] una buena suma de plata", pues "se gastarán cada año seiscientas mil libras". Como los precios de venta de la libra se mueven entre los cuatro y los ocho reales - "y en la misma tierra a dos" -, el fraile propone que "hecho el estanco se puede regular una libra con otra a quatro reales, que vienen a ser treçientos mil pesos". Todo esto si el estanco fuese gestionado directamente por oficiales de la Corona, que se ocuparían del beneficio y transporte de la hierba. No obstante, también se podría dar en arriendo a una o más personas, de forma que "den estos primeros años ciento i çinqüenta mil pesos, y cada día será mejor el arrendamiento con las çiertas experiençias de la ganancia”.

En su segundo escrito, que también consideró la Junta, fray Gonzalo del Valle ofrece noticias complementarias que justifican las magnitudes de consumo sobre las que se basan estos cálculos, 
viniendo a asegurar que "es el gasto tan grande como en España y en todas partes el tabaco y tanto como en la nueva spaña el chocolate". Ante la insistencia de la Junta, de un lado, se ve obligado a hacer hincapié en que la venta de la hierba estaría garantizada porque "es mui singular el que no la toma", ya que "los indios, indias, negros i españoles criollos de allá, y los más de los que an ido, dos veçes todos los días, otros una y otros menos". De otro lado, tiene que arriesgarse a conjeturar el número de almas o vecinos que la consumirían in situ, señalando que:

"[...] en la ciudad de la Assumpción cabeça del Paraguay con su destrito ay de españoles y indios que los siruen y doctrinas o reduçiones más de veinte mil almas de comunión [...] En las provincias del Río de la plata ai más porque solo los padres de la compañía de Jesús en el Ururay y el Tapé tienen en las reducciones (que son unas 17) más de ocho mil almas de comunión. En la gobernación de Tucumán ai muchos más indios amigos y españoles que en estotras”.

En suma, "en las tres gouernaciones del Paraguay, Tucumán y Río de la Plata ay por lo menos sesenta mil personas, de las quales los más o casi todos toman la dicha yerua".

Los cálculos del agustino cordobés continúan en su intento de probar la enorme magnitud del consumo, abriendo horizontes hacia Perú e, incluso, la propia España:

"Y no ai hombre que aya de hacer uiaje por mar o tierra en
todas aquellas partes que no compre ante todas cosas la dicha
yerua pues en el nauío que yo me envarqué solo el dicho fray
Fernando de Abreu que assiste aquí en S. Phelipe envarcó diez
y doçe arrouas y esto no para vender sino solo para él tomar y
fuera desta todos cada qual para sí enuarcaron más y menos".

Frente a la vinculación de la cosecha y tráfico de la hierba con el maltrato de los indígenas, cuyo devastador trabajo en los yerbales pintaba con horror Antonio Ruiz de Montoya, en el memorial de 1637 se supone que los habitantes de Mbracayú y los otros territorios

Anos 90, Porto Alegre, v. 24, n. 45, p. 73-100, jul. 2017 
en los que recogía la hierba resultarían beneficiados por el establecimiento del arbitrio propuesto. Incluso, se aventura que con un estanco regulado se evitarían los agravios que les hacían los "ricos i poderosos" respaldados por las autoridades civiles:

"Con este estanco no se hace daño a los naturales, antes beneficio, pues siendo (como son) indios tendrán todo el año en que trabajar, y ganar dineros, y resulta maior comodidad y beneficio a los que habitan la Prouincia del Paraguay, porque ahora los ricos i poderosos se aúnan con los gouernadores, y ellos solos goçan deste beneficio, rebendiendo esta mercadería sin permitir que otros traten en ella, sino es por su mano, y ponen los preçios a su voluntad, y como se tiene por remedio para preseruar de toda enfermedad y recuperar la salud, por qualquier precio se compra, y siendo este estanco puesto por V.Mgd se puede haçer preçio acomodado para todos".

Del mismo modo, en su segundo escrito se insistía en que el estanco les garantizaría el suministro de la hierba a un precio acomodado "porque ellos siempre la compran como todos y como los reuendedores que la traginan se la venden a como quieren podrá su magd hacerlo y darles algo más barata con que ellos y todos quedarán contentos". De esta forma, la Corona sacará suficiente provecho de "aquello que es suio y oi lo goçan quatro o seis particulares".

Por último, en los planes de fray Gonzalo del Valle entraba la creación de una figura de "teniente" puesto por el administrador o los arrendadores del estanco a cuyo cargo quedarían "los indios de Maracayú (que es donde están los montes de yerua)" que "acudirán a su beneficio" y serán pagados "en la misma yerua con largueça”. Sin duda, mayor sería su propio beneficio, pues Gonzalo del Valle cerraba su memorial suplicando que "se le despache luego la cédula ordinaria del quatro por ciento" de lo que se recaudase como consecuencia del medio que proponía.

La Junta ad hoc buscó otras fuentes de información sobre la hierba del Paraguay, cuyos provechos habían sido tan encomiados por fray Gonzalo del Valle. Se conservan cuatro pareceres que entonces 
recabó de Fernando de Abreu y Figueroa, el doctor Juan Bautista de Elorriaga, Salvador Correa de Sa e Benavides y un dictamen anónimo.

Este último ofrece informaciones sobre la hierba que destacan por su carácter médico ${ }^{30}$, aunque no deja de entrar en la cuestión de su consumo, señalando que "donde más introducido está su usso es en el mismo Paraguay y Tucumán entre los indios", aunque "en lo particular, qual y qual español la toma". La cantidad consumida, sin embargo, se cifra en menos de "100 arrobas al año que en la tierra valen muy poco y donde más caro se vende, en Potossí, es a quatro reales la libra y con una ay en una casa para un año". Aunque Gonzalo del Valle se esforzaba en comparar la hierba del Paraguay con el tabaco u otros productos americanos de extendido consumo, en este parecer se insiste que "ni en todas partes está introducido su usso como el tabaco en humo y polvo, ni como la sarza, ni como la yerba coca de el Pyrú que todas las naciones y estados lo gastan según que medicinal o biciossamente se inclinan".

En suma, la Junta era informada de que "esta yerba son raros los que la toman", de forma que no sería "capaz de [sostener] ninguna carga". A tenor del dictamen, el estanco iría a la postre "en daño de aquellos miserables indios desnudos y pobres que se ayudan con ella", pues el establecimiento del medio implicaría que el precio de la hierba bajara "para ellos", es decir, lo que les pagaban por recogerla, "y subirá al consumidor", que, salvo excepciones, también "es el mismo indio en lo general".

Por su parte, fray Fernando de Abreu y Figueroa señalaba (Madrid 14 de enero de 1637) que, sin duda, el consumo estaba extendido, pues:

“[...] no sólo es este jénero de yerba moneda usual entre la jente del paraguai, sino lexítimo sustento y alimento en especial a los naturales de todo el paraguai y su distrito de buenos ayres y los nacidos españoles especialmente nacidos en el mismo paraguai porque a éstos los engendran y engendrarán sus padres y los crían y alimentan con esta yerba”.

Anos 90, Porto Alegre, v. 24, n. 45, p. 73-100, jul. 2017 
La cosecha se elevaría "un año con otro hasta en cantidad de ocho mill arrobas poco más o menos", vendiéndose la libra "por menudo" en Buenos Aires y Tucumán "a real y medio, a beçes a dos reales y medio y quando más a tres".

No obstante, cada vez parecía más difícil recolectar la hierba porque, de un lado, habían aumentado los riesgos de "entrar muy adentro de la tierra" cerca de "los indios enemigos que la defienden" y, de otro, "porque son los indios muchos menos que antes, que son los que la ban a sacar". No sólo habría disminuido su número, sino que "estos pocos los tiene ya declarados la audiencia de las Charcas por casi libres y por de su Magestad y que no acudan al servicio personal de los españoles con tal que den el tributo que antes dauan a quien les tiene hordenado la dicha audiencia”. En atención, por tanto, a la aplicación de la real cédula de 14 de abril de 1633 sobre el trabajo personal de los indígenas ${ }^{31}$, "a de yr cada día mucho menos la cosecha de dicha yerba".

Además de que "tiene muchos costos y muchas tardanças el sacarla la tierra afuera", los intereses en torno a su "traxín” hacían que se viesen envueltos los intereses de obispos, curas, órdenes religiosas y gobernadores, con lo que el agustino Abreu y Figueroa dudaba que el estanco pudiese llevarse a la práctica realmente. Algo a lo que también se sumaba que si a los españoles "se les sacase [la cosecha de la hierba] de su poder y se les prohibiese y obligase a que goçen della por mano ajena a de resultar mucha discordia y pesadumbre".

En este momento, fray Fernando ofrece una información que demostraría lo acendrado del consumo por parte de los pobladores españoles, al asegurar que las anunciadas discordias y pesadumbres surgirían porque "los que usan en aquel distrito desta yerba de las quatro partes de la vida las tres y media gustan en usar desta yerba". La introducción del estanco sobre la hierba del Paraguay equivaldría a que "se les prohibiese que no usen della por mano propia", con lo que "no sólo an de quedar destemplados y en discordia", sino que disminuirá su cultivo, "sino fuere sólo para sí en la cantidad que lo ubiere menester ni la sacará de donde oy se da, sino fuere en el mismo grado y tan solamente para el socorro de su necesidad". En consecuencia, "es muy poco o ninguno el interés que a su Magestad se le puede seguir deste arbitrio".

Anos 90, Porto Alegre, v. 24, n. 45, p. 73-100, jul. 2017 
Pero, además, Fernando de Abreu alerta a la Junta de que la creación del estanco supondría "poner aquella jente en ocasión de conocido riesgo de discordia y alteración”, pues, además de que son de "naturaleça muy belicossa", la población de españoles se encuentra muy "sentida por los agrauios que cada dia reciuieron con quitarles los indios de su seruicio a título de que son para su Magestad, como por estar muy circumbeçinos a tantos enemigos olandeses y indios rebelados".

Por su parte, Salvador Correia de Sa presentó el siguiente dictamen, que también fecha en Madrid a 14 de enero de 1637:

"Lo que se me a preguntado acerca del gasto de la yerua del Paraguay y del Probecho que Haze a quien la toma en el tiempo que anduve por aquellas partes que fueron Passante de tres años vide que los de la Provincia del Paraguay Donde ella se Coge, ansy Indios como españoles naturales, y las mismas mugeres, todos en general toman la dicha yerua aplicándola a las más de sus enfermedades que les viene a seruir de Doctor por no averlo en aquella Provincia, en la qual hay muchos ymdios y assí juzgo que el gasto que un dia por otro Podrán hazer serán ochosientas asta nuebesientas liuras. En la Provincia del Ryo de la Plata también la toma la mayor parte de la gente, hay pocos indios, entiendo que lo que podrán gastar cada dia serán siento y sincuenta hasta Duzientas libras. En la Provinçia de tucumán también la toman en general indios y españoles, en esta Provincia me Pareçe se podrán gastar cada dia trezientas y sincuenta hasta quatrozientas liuras. En las chichas, Potosy, y chuquissaqua que fueron Partes donde estuve también la vy tomar a mucha gente, y la compré en Potosy a tres Reales de a ocho por auer falta della. Su Preçio ordinario en el Paraguay son Dos Reales, y sirue de moneda por no auer Plata. En la del Ryo de la Plata la he visto valer a Real de Plata, y a quatro Reales de Plata, en la de tucumán su preçio ordinario son quatro Reales, y la he comprado a Patacón. Esto es lo que sé, y he experimentado, en las otras Partes del Perú he oýdo decir que también la toman, no lo sé por que no lo he visto. Sé que la tierra Donde se coge es Pobre y que no tiene otro 
Refugio más que éste, y las mercadurías que a ella ban suben por este género, y por algún azúcar poco. No sé más de que pueda informar, y assý lo juro por el Ábito de Christo de que soi Professo, fecha en Madrid, 14 de Henero de 1637.

Saluador Correa de saa y benauides [rubricado]"

Es interesante destacar que Correia de Sa, en este texto que documenta su presencia en la corte madrileña todavía a comienzos de 1637 (BOXER, 1952, p. 111-112) además de presentarse a sí mismo como consumidor - lo compré, he comprado -, destaca que su conocimiento de la materia ha sido práctico - anduve, estuve, ví, sé, he experimentado, no lo sé porque no lo he visto.

A lo largo de la década de 1630 (MOLINA, 1950-1951; BOXER, 1952, p. 88-89), que es el momento de su participación en distintos hechos de armas en Paraguay, el Río de la Plata o Catamarca ${ }^{32}$ y de su matrimonio tucumano con Catalina de Velasco, Salvador Correia de Sá forjó fuertes lazos familiares y de servicio a la Monarquía superando las fronteras jurisdiccionales entre Brasil y el virreinato del Perú. Con preocupación, Lourenço de Mendonça - el corrector de erratas de Ruiz de Montoya - advertía en abril de 1636 de los peligros que a su juicio entrañaba el establecimiento de semejante alianza de dos grandes familias de Río de Janeiro y de Tucumán, alertando sobre los inconvenientes de que se le concediese el oficio de Gobernador de Río que, precisamente entonces, lo estaba llevando a la corte a pretender personalmente ${ }^{33}$. No obstante, era esa condición transfonteriza la que lo convertía en un hombre práctico en la materia de la hierba del Paraguay y hacía posible que su experiencia fuese reclamada por la Junta.

Por último, Juan Bautista de Elorriaga, quien decía basar su "relación" en lo que "he uisto y praticado asi en el Paragoay como en la provincia de tucumán donde he asistido más de doze años”, señalaba que:

"Esta yerua, señor, se llama en el idioma de los naturales donde se da Caá, cójenla en oja de árboles en Goayra 200 leguas ryo arriua de la Ciudad de la Asumpción del paragoay

Anos 90, Porto Alegre, v. 24, n. 45, p. 73-100, jul. 2017 
por los Yndios que allí hauitan que son pocos y algunos criollos que casi su vivir es como los mesmos Yndios, sin ornato ni pulicia ni forma de república ni permanencia y los más que cojen y trajinan este género son gentiles indios [...].

Los Yndios que ay por todo el Ryo arriua hasta Goayra desde buenos ayres son los más gentiles y bárbaros campestres y desnudos sin labranças ni otra ocupación de trauajo ni permanencia oy en una parte y mañana en otra sin más albergue que unas esteras de juncos gruesos que las lleuan a cuestas a donde quiera que van, andan ordinariamente por las tierras del Paraná (que es nombre proprio del dicho Ryo de la Plata) y son los que siruen de bogar en las canoas y balsas de los pasajeros que andan aquella nauegación y se mudan a trechos por tantas jornadas, pagáseles en camisetas, chaquieras, cuchillos y otras cosas de poca importancia y ellos ni la compran ni tratan de yerua, sino de sustentarse de montería y de pescado y raízes de la tierra, los pasajeros además del concierto les van dando el tiempo que nauegan alguna yerua porque vayan contentos y gratos por el riesgo de la nauegación y vidas que pende dellos. [...]".

Después de rescatarla "a los dichos Yndios de Goayra por algunas comidas, cuchillos, chaquiras, lienço de algodón y camisetas dello y de sayal y otras menudencias", Asunción sería el primer destino de la hierba, siendo allí "el trato y comercio menor de la plaça y la moneda usual por que en ella no se maneja oro ni plata". Aquí, "la toman en agua caliente molida y cernida, casi todos los días, que por la ociosidad de no tener comunicación de otras partes o por la costumbre es vicio introducido por entretenimiento y así los que la continúan tanto andan pálidos y descoloridos".

Desde Asunción, la hierba llega a la provincia de Tucumán en expediciones que organizan algunos vecinos que comercian con conservas de azúcar y "que hazen un viaje tan penoso y largo [...] por ser 500 leguas las que se andan parte por nauegación de balsas y canoas y parte por tierras despobladas y con carretas a tiro de

Anos 90, Porto Alegre, v. 24, n. 45, p. 73-100, jul. 2017 
bueyes y en la yda y buelta se tardan un año poco más o menos". En esta provincia, sólo la toman los hombres, aunque no con tanto "vicio" como en Asunción y "los naturales no la gastan ni compran una libra y en ésta tiene cada qual para diez vezes".

Los vecinos de Asunción "llegan asta las ciudades de Santiago del Estero y a la de Córdoua donde reparten la mayor parte de la yerua entre sus amigos y correspondientes". Si la venden, "los pulperos la dan a dos reales la libra y no son treinta arrouas las que en cada lugar de Tucumán se venden en tienda", mencionándose, además de Santiago del Estero y de Córdoba, los lugares de Talavera de Madrid, Nueva Rioja de Todos los Santos, Valle de Lerma y San Juan Bautista de la Paz, arrasada por "los indios de Calchaqui". La yerba también alcanza Buenos Aires, donde "vale más barata”, Santa Fe de Garay, pero que "tendrá cien vezinos pobre y poco abastecida de todo lo necesario no se maneja dinero", Corrientes, apenas un "asiento de quatro ranchos de paxa", y Río Bermejo, que se "despobló por hauer muerto los indios a sus moradores, que serían quatro o cinco vezinos con algunos domésticos y familia, que era paso y refugio de los que yvan del Paragoay a Tucumán”.

Fuera de aquí, aunque "mucha noticias dan desta yerua los que salen de las dichas Prouincias a otras", no se usaría demasiado en las "contiguas a ellas", ni en Potosí ni en Chile, "adonde se pudiera hauer introducido y he uisto que algunos confiteros que han ynuiado por ella no la han podido vender y se les ha podrido parte y pasado otra".

En suma, a su juicio los trescientos mil pesos que calculaba recaudar fray Gonzalo del Valle no llegarían, en el mejor de los casos, a los treinta mil. Además, si se hiciera el estanco, sería imposible "asegurar el registro de lo que se sacaua del paragoay a otras partes" viniendo en detrimento de "aquella gente miserable del paragoay que con el corto rescate que dan a los indios de Goayra sustentan el referido modo de comercio en su república en lugar de moneda corriente".

Sobre la base de estos testimonios, la Junta (28 de enero de 1637) consultó a Felipe IV que el consumo de la hierba era indudable, pues "ha pasado a deliciossa en tanto grado que por agasajo i conversación se usa della no una vez solamente al día, sino con

Anos 90, Porto Alegre, v. 24, n. 45, p. 73-100, jul. 2017 
repetición algunas, que también la demasía que en esto ay la ha hecho preciosa". No obstante, "no es en tanta cantidad ni con mucho su gasto según en el memorial se refiere". Además, la experiencia demostraba que la Corona ya había fracasado al establecer un estanco sobre el tabaco, producto que "era de tanto consumo, $\mathrm{i}$ que le extraen con introdución tan universal i dilatada".

La propuesta de la Junta era, en suma, que "se podía introducir [...] alguna imposición tolerable, con proporción a la posibilidad de los habitadores, al trabajo que ponen en coxerla, $i$ al interés que en la venta tienen", no sin que antes se recabase el parecer de los gobernadores de Paraguay y de Buenos Aires, la real Audiencia y el virrey del Perú. Concluida, así, la discusión sobre los memoriales de fray Gonzalo del Valle en el seno de la Junta, una serie de reales cédulas datadas en San Lorenzo del Escorial a 31 de octubre de 1637 fueron enviadas al virrey del Perú, Conde de Chinchón, a las audiencias de Charcas y Lima y a los gobernadores de Paraguay y Río de la Plata, con el mandato de que "informe y envíe su parecer sobre la conveniencia de hacer estanco, beneficiar y administrar por parte de la Real Hacienda una yerba que llaman del Paraguay y crece especialmente en esas provincias, y qué derechos se podrían introducir en ella" ${ }^{34}$. No obstante, como recoge Gaspar de Escalona y Agüero en su Garofilacium Regium Perubicum, "conociendo su importancia su Magestad, y su comercio, y gasto, mandó imponer sobre ella algún derecho; pero no se ha dispuesto por lo impraticable, mediante ser cosecha de Indios, y poco su interés, y su traxín de incierta, y difícil aueriguación"35.

Quedaba, sin embargo, una delicada cuestión sobre la que la Junta de la hierba del Paraguay había tenido también que declararse: la concesión del cuatro por ciento de la imposición a un religioso, un asunto que revelará alguna circunstancia de especial importancia. Lorenzo Ramírez del Prado y Rodrigo Jurado se mostraron partidarios a la concesión, sugiriendo que su condición eclesiástica no le impedía recibir tal beneficio, aunque el fraile no hubiese llegado a un acuerdo previo con su orden. No entraban los dos letrados en que el agustino se hubiese ausentado de Indias y llegado a Madrid sin contar con la licencia de su prelado. En cambio, Bartolomé Morquecho se oponía a que se le diesen los despachos para que el 
religioso gozase el cuatro por ciento, porque, además de no haber viajado con licencia, "jamás ha estado en la parte en la que se coxe la Hierva i según la relación que ha dado en la junta i lo que habló en ella quando se le permitió entrar no mostró de estar capaz en la materia sino por lo oído a otros ausentes".

Por tanto, fray Gonzalo del Valle, que sí había estado en Indias, no era tan práctico en la hierba del Paraguay como había querido dar a entender. Y, a juicio del consejero Morquecho, esta falta de un conocimiento experimentado rebajaba la credibilidad que su propuesta podía merecer.

Como expusieron en la consulta que elevaron al monarca, los miembros de la Junta habían "solicitado todas las noticias que ha podido así por lo que se ha escrito de esta Hierva en las Historias i libros, como de personas inteligentes i práticas i que an estado en aquella Provincia". Es decir, la Junta recurrió tanto a la información nacida de una autoridad textual, en principio de naturaleza histórica y médica, como a la resultante de un conocimiento basado en la experiencia práctica de distintas personas.

Fue el propio Gonzalo del Valle quien propuso los nombres de varios personajes que, encontrándose entonces en Madrid, responderían a esa condición de inteligencia y practicidad en el conocimiento de la hierba. Entre ellos, se hallaba Salvador Correia de Sá e Benavides y que, según el fraile agustino, "enuarcó mucha [hierba] y oi aquí [en Madrid] no está sin ella”.

Aparte del ilustre descendiente de Mem de Sá, que, a la sazón, estaba "proueído por Gobernador del Rio Jenero en el Brasil", el fraile agustino sugirió a la Junta que podía recabar noticias sobre la hierba del Paraguay de Vasco Mascarenhas, quien acababa de regresar del Brasil, de contraer matrimonio con Jerónima de la Cueva y, en consecuencia, de ser agraciado con el título condal de Óbidos (CUNHA, 2009, p. 226); del criollo de Popayán Diego de Ribera Maldonado, con larga experiencia en oficios de gobierno en el virreinato peruano, de Ica y Potosí a Tucumán y Buenos Aires ${ }^{36}$; de Guillén López de Palacios, contador vinculado al mundo de la hacienda rioplatense (MAGDALENO, 1954, p. 596; HEREDIA HERRERA, 1990, p. 336, 372, 382); de fray Miguel de Vereo, provincial de los mercedarios de $\mathrm{Cuzco}^{37}$ (PALACIO, 1999); y, por último, del limeño fray Fernando

Anos 90, Porto Alegre, v. 24, n. 45, p. 73-100, jul. 2017 
de Abreu y Figueroa, también agustino, autor de no pocas propuestas en materia de regalías indianas (SANTIAGO VELA, 1913, p. 8-12).

La Junta solicitó en efecto, como hemos visto, a Correia de Sá y a Abreu y Figueroa que presentaran sendos escritos sobre el consumo y tráfico del mate a la luz de su propia experiencia, declinando el concurso de los otros individuos propuestos por Gonzalo del Valle. Además, decidió recurrir al del vizcaíno Juan Bautista de Elorriaga, antiguo secretario de cámara de Julián de Cortázar, obispo de Tucumán, que, tras desembarcar con el nuevo prelado en Buenos Aires, "fue con él a la çiudad de la Asumpzión del Paraguay a consagrarse, en que padeció grandes trauaxos". Ya en Tucumán, asistió a Cortázar en la visita de su obispado en 1622 (LEVILLIER, 1926, p. 308-323) “y después él solo la volvió a haçer de la mayor parte dél"38. Se entiende, así, que el propio Juan Bautista de Elorriaga afirmase ante la Junta de 1637 que su extenso parecer sobre la hierba se basaba en todo lo que "he uisto y praticado así en el Paragoay como en la provincia de Tucumán donde he asistido más de doze años".

Congruente con su criterio de asesorarse con "personas inteligentes i práticas i que an estado en aquella Provincia”, la Junta había elegido informarse con Salvador Correia de Sá, Fernando de Abreu y Juan Bautista de Elorriaga. Los tres contaban con experiencia directa de las tierras donde se producía o se consumía ampliamente la hierba del Paraguay. Incluso resulta elocuente que una parte las dudas que rodean el testimonio de Gonzalo del Valle tienen que ver con que sí había estado en Indias, pero en "la parte en la que se coxe la Hierva".

Esta insistencia en el conocimiento directo evoca la cuestión ineludible de cómo tomaba sus decisiones el Consejo en las materias propias de su despacho y gobierno (BRENDECKE, 2012). A la altura de 1637, tanto el Consejo de Indias como el de Estado ya habían tenido que consultar "sobre la pretensión que tienen los naturales de las Indias llamados criollos de que uno dellos sea de ordinario consejero deste consejo". El origen de estas consultas, evacuadas en 1635, se encontraba en una propuesta del Virrey del Perú, Conde de Chinchón, quien había encarecido "quán conueniente es que aya en los consejos personas notiçiosas de las prouinçias que se gouiernan por ellos". El propio Felipe IV se habría mostrado partidario 
de conceder dicha merced "por los exemplares de los conssejos de Aragón, Italia y Portugal" 39.

Como se ve, la petición venía a suponer que el Consejo de Indias tuviese en cuenta, aunque fuese sólo para la designación de una de sus plazas, el criterio de naturaleza a la hora de establecer una parte de su composición ordinaria. De hecho, el argumento pasaba por insistir en que el conocimiento práctico de las materias indianas que tenían los "llamados criollos" mejoraría la toma de decisiones en el seno del Consejo y, sin duda, constituye un hito importante para el mejor conocimiento de la percepción y autopercepción del fenómeno criollo (ARROM, 1951; PAGDEN, 1987; BRADING, 1991; PONCE, 1997; ALBERRO, 2000). No obstante, la propia diferencia indiana terminó siendo invocada para argumentar contra la posibilidad de que hubiera una plaza de asiento reservada para criollos en el Consejo de Indias, pues la enorme extensión y diversidad de los territorios americanos haría imposible encontrar un criollo que tuviera conocimiento de todos ellos ${ }^{40}$.

Como debía ofrecer un panorama general del hipotético mercado de la hierba del Paraguay, distinguiendo los varios grupos de posibles consumidores, en su memorial de 1637 fray Gonzalo del Valle asegura que tomaban la hierba "los indios, indias, negros i españoles criollos de allá, y los más de los que an ido", De esta forma, su memorial revela un uso del término "criollos" que permite identificarlos claramente como "españoles criollos de allá", que no deberían confundirse con "los que an ido". Igualmente, el agustino y los autores de otros pareceres tenidos en cuenta por la Junta destacan prácticas de consumo distintas entre españoles criollos y españoles no naturales de Indias, con observaciones como la hecha por Fernando de Abreu sobre la hierba era sustento y alimento para los españoles "nacidos en el mismo paraguai porque a éstos los engendran y engendrarán sus padres y los crían y alimentan con esta yerba".

El arbitrio del agustino cordobés ofrece, como vemos, una cantidad importante de noticias sobre la producción, distribución y consumo de la hierba mate a mediados de la década de 1630, ofreciendo testimonios que permiten contextualizar mejor el paisaje trazado por los preeminentes textos de Antonio Ruiz de Montoya. Además, la discusión sobre sus propuestas muestra que los criterios con los que

Anos 90, Porto Alegre, v. 24, n. 45, p. 73-100, jul. 2017 
la Monarquía deseaba construir nuevos saberes en materias locales de Indias superaban lo meramente textual para adentrarse en la experiencia y la práctica. Por ello, argumentos como el conocimiento directo de las provincias de Paraguay, o del Río de la Plata y del Perú donde la hierba se consumía, fueron esgrimidos para elegir quiénes debían actuar como expertos sobre cuyos dictámenes fundamentar la toma de decisiones de la Corona. En ese sentido, el concurso de criollos parece haber sido reconocido como una necesidad indiscutible, pese que, al mismo tiempo, la Monarquía desoía por entonces las voces que reclamaban abiertamente un puesto de asiento para los criollos en el seno del Consejo de Indias.

\section{THE 1637 EXPEDIENT OF THE “BENEFICIAL" YERBA MATE FROM PARAGUAY. EXPERIENCE AND PRACTICALITY ON THE CONSTRUCTION OF LOCAL KNOWLEDGES ON AMERICAN MATTERS ACROSS THE ATLANTIC}

Abstract: The proposal of a new tax on the consumption of Paraguayan yerba mate in 1637 is the starting point to analyze the mechanisms used by the Spanish West Indies government in order to take some of its decisions in the midseventeenth century. These decisions were taken by the the fabrication of a particular local knowledge constructed on practical and experienced knowledges. To search and find people who could testify that kind og knowledge became a prior requirement to decisions just in a time when the American criollos tried to enter the Consejo de Indias. Previously unpublished documents about the production, distribution and consumption of yerba mate from Paraguay, Rio de la Plata and Peru, even to reach the distant market of the Spanish Habsburg court, are also offered.

Keywords: Local knowledges. Practical knowlegdes. Spanish West Indies Government. Paraguay. Yerba mate (Ilex Paraguaiensis).

\section{Notas}

${ }^{1}$ Esta investigación ha sido realizada en el marco del proyecto MINECO HAR2014-54492-P financiado por el Gobierno de España. Sobre la importancia de los procuradores de la Compañía, MARTÍNEZ-SERNA, 2008.

Anos 90, Porto Alegre, v. 24, n. 45, p. 73-100, jul. 2017 


\section{El arbitrio de la hierba "provechosa" del Paraguay...}

${ }^{2}$ [Memorial]: Señor. Antonio Ruiz de Montoya de la Compañia de Iesús, y su procurador general de la prouincia del Paraguay, dize: que estando probibido por cédulas, y ordenes reales, so graues penas, que los portugueses del Brasil no puedan entrar en la dicha pronincia. S.l. [Madrid]: n.i., n.a. [1639?]; y [Memorial:] Háseme mandado, que assi como representé a Su Magestad, y señores del Real Consejo, en vn memorial impresso los agranios enormes, que los vezinos de la villa de S. Pablo, y demas villas de la costa del Brasil han hecho, y al presente hazen a los Indios christianos, e infieles de las promincias del Paraguay, y Río de la Plata. S.l. [Madrid]: n.i., n.a. [1639?].

${ }^{3}$ En Madrid: en la imprenta del Reyno, 1639. Privilegio dado en Madrid, 5 de julio de 1639.

${ }^{4}$ En Madrid: por Iuan Sánchez, 1639.

${ }^{5}$ En Madrid: Por Diego Díaz de la Carrera, 1640.

${ }^{6}$ En Madrid: por Iuan Sánchez, 1640.

${ }^{7}$ La impresión de los volúmenes había concluido en diciembre de 1639, pues sus respectivas tasas están fechadas todas a 5 días de dicho mes.

${ }^{8} \mathrm{JARQUE,} \mathrm{Francisco.} \mathrm{Vida} \mathrm{prodigiosa} \mathrm{en} \mathrm{lo} \mathrm{vario} \mathrm{de} \mathrm{los} \mathrm{sucesos} \mathrm{[...]} \mathrm{del} \mathrm{Venerable} \mathrm{Padre}$ Antonio Ruiz de Montoya. Zaragoça: por Miguel de Luna, impresor, 1662, p. 523. ${ }^{9} \mathrm{Al}$ volver a Indias, el jesuita embarcó nada menos que "veinte cajones de los quatro libros" que había impreso en Madrid con licencia real "de la lengua guaraní [...] todo en lengua del Paraguay y del Río Marañón, para que los curas aprendan la lengua y puedan predicar y ayudar a aquella nueva combersión". Archivo General de Indias, Sevilla [AGI], Contratación, 5426, 79.

10 "Aprovación del muy ilvstre Doct. D. Lorenço Hurtado de Mendoza, Prelado Obispo electo del Río de Ianeiro", Madrid, 7 de marzo de 1639. Como ya se ha mencionado, esta aprobación aparece tanto en el Tesoro, el Catecismo y el Arte y bocabulario.

${ }^{11}$ Inventario de la librería del señor D. Lorenzo Ramírez de Prado, [S.l. [Madrid]: n.i, n.a. [c.1660]. "Relación del Martirio de unos Iesuitas, en Paraguay, 1628", Inventario..., fol. 22 v. Relación del martirio de los padres Roque Goncález de Santacruz, Alonso Rodríguez, Inan del Castillo de la Compañia de Iesus, padecido en el Paraguay, a 16 de noviembre de 1628. Al Rey Don Felipe N.S. El P. Juan Baptista Ferrufino Procurador General de la Provincia del Paraguay. [S.l.: n.i., n.a. [c. 1633?]. Sobre los años de la procuración general de Ferrufino, de 1632 a 1636, que implica la hipotética datación de esta obra, STORNI, 1980, p. 101; “Litterae Societatis de Paraguay, Antuerp. 1636”, fol. 28v. Litterae annuae provinciae Paraquariae Societatis Iesu ad admodum R.P. Mutium Vitellescum eiusdem Societatis Praepositum Generalem missae a R.P. Nicolao Duran Paraquariae Praeposito Provinciale; eius nomine ac iussu scriptae a P. Iacobo Rançonier Belga eiusdem Societatis, Antuerpiae: Typis J. Mersius, 1636; y "Conquista espiritual del Paraguay, por Antonio Ruiz, Mad. 1639"; “Tesoro de la lengua Guaraní, de Antonio Ruiz, en Madrid 1639”; "Vocabulario 


\section{Fernando Bouza}

de la lengua Guaraní, por Antonio Ruiz, Madrid 1640”; y "Catecismo de la lengua Guaraní, por Antonio Ruiz, Mad. 1640" (Inventario..., respectivamente, fols. 15v; 43r; 4r; y 8r.). Cfr. PENA SUEIRO, 2013.

${ }^{12}$ PINELO, Antonio de León. Qüestión moral, si el chocolate quebranta el ayuno eclesiástico. Madrid: Por la viuda de Juan Gonçález, 1636.

${ }^{13}$ León Pinelo, Qüestión moral, fol. 63r.

${ }^{14} \mathrm{Idem}$, fol. 63 r.-v.

${ }^{15} \mathrm{Idem}$, fol. $64 \mathrm{v}$.

${ }^{16}$ Tassa de los precios a que se han de vender las mercancías y otras cosas, En Madrid: Por Iuan Gonçález, 1628, fol. 9r.

${ }^{17}$ Madrid, 5 de abril de 1633, Archivo de la Corona de Aragón, Barcelona, Consejo de Aragón, legajo 54-196.

${ }^{18}$ Archivo Histórico Nacional, Madrid, [AHN], Ministerio de Asuntos Exteriores, Obra Pía, caja 43, Papeles de Lorenzo Ramírez de Prado. Se remite a esta referencia para todas las citas textuales a la documentación concerniente a esta negociación que se harán a continuación en texto y notas.

${ }^{19}$ Poco se sabe de este personaje, que debe ser identificado con el fraile del mismo nombre que en SANTIAGO VELA, 1931, p. 84-85, se recuerda como hijo del Convento de San Agustín de Córdoba y que murió en México en 1682 después de haber alcanzado la dignidad de Provincial de la Provincia del Santísimo Nombre de Jesús de Nueva España entre 1675 y 1678. En sus algo tumultuosos años novohispanos (RUBIAL, 1990, p. 51-53), publicó una Palestra de varios sermones [...]. En México: por la Viuda de Bernardo Calderón, 1676; y un Espejo de varios colores [...]. En México: por Francisco Rodríguez Lupercio, 1676. Pero, más cerca de la discusión sobre la hierba del Paraguay, cuando era lector en teología, dio a la imprenta el Triunfo de Iudith, y vitoria de Bethulia. En Madrid: por Diego Díaz, 1639, un raro impreso dedicado a João Coutinho, arzobispo de Évora e hijo del Conde de Vila Franca.

${ }^{20}$ Fray Gonzalo sólo invoca una autoridad textual, al afirmar que "destos árboles escriuió en nuestros tiempos el doctor Çisneros médico famoso del Potosí en un libro que compuso", que no hemos llegado a identificar.

21 "[...] el dicho religioso no viene a estos Reynos con licencia de su prelado ni de Virrey, Presidente ni otro Gobernador", consulta de la Junta al rey, 28 de enero de 1637.

${ }^{22}$ [Antonio de León Pinelo], Relación de los servicios del Padre Maestro Fr. Fernando de Abreu, de la Orden de San Agustin, S.l. [Madrid]: n.i., n.a. [1649], AGI, Indiferente General, 193, 51.

${ }^{23}$ La condición religiosa de Gonzalo del Valle parece encontrarse detrás de este hecho. Como había viajado sin licencia de su orden, no se habría compuesto 


\section{El arbitrio de la hierba "provechosa" del Paraguay...}

previamente con ella para promover el arbitrio de la hierba. Dicha condición, además, abría dudas sobre que su eficacia como recaudador, siendo poco capaz de "levantar los ánimos, que en partes tan remotas tiene peligro".

${ }^{24}$ Dos décadas después, un Bartolomé del Valle, natural de Puente de Don Gonzalo, fue encausado en Cartagena de Indias en un proceso por bigamia. En una de las declaraciones, relata que tiene dos hermanos agustinos, uno se llama fray Pedro del Pino Valle y reside en Montilla; el otro es "fray gonçalo del valle religioso assimismo del señor San Agustín". Gracias a las indagaciones hechas en este proceso es posible saber que el promotor del medio de la hierba del Paraguay era hijo de Pedro Alonso Bermejo y María del Valle. AHN, Inquisición, 1621, 7. ${ }^{25}$ Corónica moralizada del Orden de san Augustín en el Perú, con sucesos egenplares vistos en esta Monarquía. Barcelona: Por Pedro de Lacavallería, 1639, p. 318-319.

${ }^{26}$ Conquista espiritual..., fols. 29-32.

${ }^{27}$ Conquista..., fols. 8-9. Cfr. MELIA, 1982 con su expresiva evocación de la "erva infernal".

${ }^{28}$ Conquista..., fol. 9v.

${ }^{29}$ Conquista..., fol. $1 \mathrm{v}$.

30 "Su forma es como la de el cen, en el tamaño y en el color de la oxa; su sabor ingrato al gusto, el olor, orrible. Como de sumaque, la calidad caliente y seca, su propiedad agitar los umores detenidos y colectos en el estómago, y sus efectos, provocar a vómitos, sirviéndola el aguacaliente, o tépida en que se toma y bebe de vehículo cosida en ella esta yerba, o echada en polbos en cantidad de una onza, y comforme es la del agua que se bebe sucede la operación violenta y aspresurada que haze bolbiéndosse con los umores que halla en el estómago y solo para este efecto es su usso sin que se le halle otra virtud oculta o conocida de lo qual se averigua no ser apta para mantener ni deleytable para embriagar como no se podrá creer esto de el Cen y Ruibarbo, siendo tan purgante como estos dos medicamentos y más activo que el cohombrillo amargo. [...] con este Regimiento se precerban de graues enfermedades por ser de difícil digestión y que crian crudessa y flema los mantenimientos que tomen, estos mismos se ualen como pobres de coxerla por la esterilidad de la tierra y truecan y rescatan a cosas que an menester [...] ni está en las Boticas ni receptada por los médicos, pues en caso de necesidad sola el agua caliente suplirá su falta".

${ }^{31}$ La relevancia de esta real cédula hizo que Ruiz de Montoya la incorporara a su Conquista espiritual..., fols. 99v.-100v.

${ }^{32}$ Con motivo de su reclamación de una encomienda de indios en Tucumán, el propio Almirante presentó, en 1636, un interesante memorial en el que constan sus servicios de esos años, AGI, Charcas, 101, 61A.

${ }^{33}$ Lourenço de Mendonça a Su Majestad, Río de Janeiro, 4 de abril de 1636, AGI, Charcas, 101, 61F.

Anos 90, Porto Alegre, v. 24, n. 45, p. 73-100, jul. 2017 
${ }^{34}$ Tomo la descripción de <pares.mcu.es>, registro correspondiente a AGI, Buenos Aires, 2, L. 5, fol. 269v. LIBROS REGISTROS-CEDULARIOS, 1984, p. 304-305.

${ }^{35}$ En ced. Real de postr. de Otubr. 637. Gaspar de Escalona y Agüero, Arca limensis. Gazophilatium regium perubicum. [Madrid: Imprenta Real, 1647], p. 236. La real cédula también es citada en LAMAS, 1874, p. 208.

${ }^{36}$ Ribera - o Rivera - ofrece una semblanza de sus servicios indianos en AGI, Filipinas, 163, 2.

${ }^{37}$ Gonzalo del Valle propone que también se podría convocar a "su compañero", sin indicar su nombre. Cuando regresó a Perú, Miguel de Vereo lo hizo en compañía de dos compañeros que lo habían acompañado desde Indias y que se llamaban fray Juan de Bustamante y fray Francisco de Cepeda. AGI, Contratación, 5419, 47.

${ }^{38}$ AGI, Indiferente, 194, 37. Elorriaga siguió a Cortázar desde Tucumán a la nueve sede de Santa Fe de Bogotá, donde el prelado falleció en 1630.

${ }^{39}$ Archivo General de Simancas, Estado, 2655, 37. Consultas de Madrid, 28 de abril, 2 de mayo y de 18 de junio de 1635 .

${ }^{40}$ En una negociación en la que Estado se mostró bastante más partidario que Indias a acceder a lo sugerido en las consultas, salen a relucir abiertamente los temores a que esa plaza ordinaria pudiera ser utilizada como argumento favorable a los criollos en la polémica de la alternativa eclesiástica.

\section{Referências}

AGUILAR, Jurandir Coronado. Conquista espiritual. A história da evangelização na Província Guairá na obra de Antonio Ruiz de Montoya, S.I. (1585-1652), Roma: Editrice Pontificia Università Gregoriana, 2002.

ALBERRO, Solange. La emergencia de la conciencia criolla: el caso novohispano. In: MAZZOTTI, José Antonio (ed.), Agencias criollas. La ambigüedad "colonial" en las letras hispanoamericanas. Pittsburgh: Instituto Internacional de Literatura Iberoamericana, 2000, p. 55-71.

ARROM, Juan José. Criollo: definición y matices de un concepto. In: Hispania. American Association of Teachers of Spanish and Portuguese, v. 34, n. 2, p. 172-176, 1951.

BOXER, Charles R. Salvador de Sá and the struggle for Brazil and Angola. 1602-1686. London: The Athlone Press, 1952.

BRADING, David A. The First America. The Spanish monarchy, Creole patriots and the Liberal state, 1492-1867, Cambridge; New York: Cambrigde University Press, 1991.

Anos 90, Porto Alegre, v. 24, n. 45, p. 73-100, jul. 2017 


\section{El arbitrio de la hierba "provechosa" del Paraguay...}

BRENDECKE, Ardnt. Imperio e información. Funciones del saber en el mundo colonial español. Madrid: Iberoamericana Vervuet, 2012.

CARDIM, Pedro Almeida. Todos los que no son de Castilla son yguales. El estatuto de Portugal en la monarquía española en tiempos de Olivares. Pedralbes, v. 28, 2008, p. 521-552.

CUNHA, Mafalda Soares da. Títulos portugueses y matrimonios mixtos en la Monarquía Hispánica. YUN, Bartolomé (Dir.). Las redes del Imperio. Élites sociales en la articulación de la Monarquía Hispánica, 1492-1714. Madrid: Marcial Pons, 2009, p. 205-232.

CURTO, Diogo Ramada. O Padre Lourenço de Mendonça: entre o Brasil e o Peru (c. 1630 - c. 1640). Topoi, v. 11, n. 20, p. 27-35, 2010.

DÍAZ MORENO, Félix. El control de la verdad: los Murcia de la Llana una familia de correctores de libros. Arbor, v. 185, n. 740, p. 1301-1311, 2009.

FEITLER, Bruno Guilherme. Usos políticos del Santo Oficio portugués en el Atlántico (Brasil y África Occidental). El período filipino. Hispania Sacra, v. 119, p. 269-291, 2007.

GARAVAGLIA, Juan Carlos. El mercado interno colonial y la yerba mate (siglos XVI-XIX). Nova Americana, n. 4, p. 163-210, 1981.

GARAVAGLIA, Juan Carlos. Mercado interno y economía colonial. Tres siglos de historia de la yerba mate. México: Grijalbo, 1983.

DE CASTELNAU-L'ESTOILE, Charlotte; COPETE, Marie-Lucie; MALDAVSKY, Aliocha; ZUPANOV, Ines G. (edrs.). Missions d'évangélisation et circulation des savoirs. XVIe-XVIIIe siècle. Madrid: Casa de Velázquez, 2011.

HEREDIA HERRERA, Antonia (dira). Catálogo de las consultas del Consejo de Indias (1637-1643). Sevilla: Diputación Provincial de Sevilla, 1990.

LAMAS, Andrés. Historia de la conquista del Paraguay, Rio de la Plata y Tucumán escrita por el P. Pedro Lozano de la Compañía de Jesús, I. Buenos Aires: Casa Editora Imprenta Popular, 1874.

LEVILLIER, Roberto. Papeles eclesiásticos del Tucumán. Documentos originales del Archivo de Indias. Volumen I. Madrid: Imprenta de Juan Pueyo, 1926.

LIBROS registros-cedularios del Río de la Plata (1534-1717). Catálogo, v. I. Buenos Aires: Instituto de Investigaciones de Historia del Derecho, 1984.

MAGDALENO, Ricardo. Catálogo XX del Archivo General de Simancas. Títulos de Indias. Valladolid: Patronato Nacional de Archivos Históricos, 1954. 


\section{Fernando Bouza}

MARTÍNEZ-SERNA, José Gabriel. Procurators and the Making of the Jesuits' Atlantic Network. In: BAILYN, Bernard; DENAULT, Patricia L. (Ed.). Soundings in Atlantic History. Latent Structures and Intellectual Currents, 1500-1830. Cambridge: Harvard University Press, 2009, p. 181-209.

MELIÀ, Bartomeu. Assembleia guarani de 1630 denuncia exploração através do plantio da erva infernal. Porantim, n. 39, maio 1982, p. 6.

MOLINA, Raúl A. Salvador Correa de Saa y Benavídez. Un héroe americano ligado al Brasil y a la Argentina. Instituto Argentino de Ciencias Genealógicas. Revista, 9-10 (195-1951), p. 261-309.

NEUMANN, Eduardo Santos. Letra de indios. Cultura escrita, comunicação e memoria indígena nas Reduções do Paraguai. São Bernardo do Campo: Nhanduti Editora, 2015.

PAGDEN, Anthonty. Identity Formation in Spanish America. In: CANNY, Nicholas; PAGDEN, Anthony (Ed.). Colonial Identity in the Atlantic World, 15001800. Princeton: Princeton University Press, 1989, p. 51-93.

PALACIO, Eudoxio de Jesús. Provinciales de Cuzco de la Orden Mercedaria (15561944). Roma: Instituto Histórico de la Orden de la Merced, 1999.

PALOMO, Federico. Religious procurators and cultural circulation in the early modern Portuguese world: prints, images, and relics from Japan in the António Cardim's Roman journey (1644-1646). E-Journal of Portuguese History, v. 14, n. 2, 2016.

PENA SUEIRO, Nieves. América en la librería de Don Lorenzo Ramírez de Prado, Consejero de Indias. Revista Chilena de Literatura, v. 85, p. 247-270, 2013. PÉREZ SAMPER, María de los Ángeles. La integración de los productos americanos en los sistemas alimentarios mediterráneos. XIV Jornades d'Estudis Històrics Locals. La Mediterrània área de convergència de sistemes alimentaries (segles V-XVIII). Palma de Mallorca: IEB, 1996, p. 89-148.

PIZZORUSSO, Giovanni. I satelitti di Propaganda Fide: il Collegio Urbano e la Tipografia Poliglotta. Mélanges de l'École Française de Rome, n. 116-2, 2004, p. 471-498.

POLLACK, John H. Native American words, early American texts. Pennsylvania: University of Pennsylvania, 1 jan. 2014. Disponível em: <http://repository. upenn.edu/dissertations/AAI3670950>.

PONCE, Pilar. Certezas ante la incertidumbre. Élite y cabildo de Quito en el siglo XVII. Quito: Abya-Yala, 1997. 


\section{El arbitrio de la hierba "provechosa" del Paraguay...}

ROUILLON ARRÓSPIDE, José Luis. Antonio Ruiz de Montoya y las reducciones del Paraguay. Asunción: Centro de Estudios Paraguayos Antonio Guasch, 1997. RUBERT, Arlindo. O prelado Lourenço de Mendonça, $1^{\circ}$ bispo eleito de Rio de Janeiro. Revista do Instituto Histórico e Geográfico Brasileiro, n. 311, 1976, p.13-33. RUBIAL, Antonio. Una monarquía criolla. La provincia agustina de México en el siglo XVII. México: Consejo Nacional para la Cultura y las Artes, 1990.

SÁNCHEZ, Jean-Pierre. Myths and Legends in the Old World and European Expansionism on the American Continent. HAASE, Wolfgang; REINHOLD, Meyer. (Ed.). The classical tradition and the Americas. European images of the Americas and the classical tradition. v. 1. Berlin: Walter de Gruyter, 1994, p. 180-240.

SANTIAGO VELA, Gregorio de. Ensayo de una biblioteca ibero-americana de la Orden de San Agustín. v. I, A-Ce. Madrid: Imprenta del Asilo de Huérfanos del Sagrado Corazón de Jesús, 1913.

SANTIAGO VELA, Gregorio de. Ensayo de una biblioteca ibero-americana de la Orden de San Agustin. v. VIII, U-Z. Anónimos, adiciones y enmiendas. Madrid: Imprenta del Asilo de Huérfanos del Sagrado Corazón de Jesús, 1931.

STORNI, Hugo. Catálogo de los jesuitas de la Provincia del Paraguay (Cuenca del Plata) 1585-1768. Roma: Institutum Historicum Societatis Iesu, 1980, p. 101.

VÁZQUEZ DE ESPINOSA, Antonio. Compendio y descripción de las Indias Occidentales. Transcrito del manuscrito original por Charles Upson Clark. Washington: Smithsonian Institution, 1948.

WILDE, Guillermo. Religión y poder en las misiones de guaranies. Buenos Aires: SB, 2009.

Recebido em: 22/12/2016

Aprovado em: 01/03/2017

Anos 90, Porto Alegre, v. 24, n. 45, p. 73-100, jul. 2017 